\title{
The devil is in the detail
}

\section{Royston Goodacre}

Published online: 11 January 2013

(C) Springer Science+Business Media New York 2013

Welcome to the Ninth Volume of Metabolomics!

It is now a few days after the winter solstice and as this year draws to an end, and we have all successfully survived the dawn of the next B'ak'tun from the Mayan calendar with its misinterpretations, it is time to cast our minds back on 2012. For my home country it has been a successful year with several significant accomplishments: the Queen's Diamond Jubilee celebrations brought great joy to most of the country and in July and August London hosted a very successful XXX Summer Olympic Games. One of the legacies from these Olympics was not just the inspiration that it has given many people, along with the sense of happiness that emanated throughput the UK in August and beyond, but the very generous donations and funding that have led to the initiation of two UK-based Phenome Centres in London (Saini 2012). This is a wonderful opportunity to bring metabolomics closer to patient care and we shall all be watching with interest to see the fruits of Jeremy Nicholson and colleagues' work in this area. Similar activities have been initiated throughout the world and I would encourage you all to read about these in an article entitled 'Metabolomics across the globe' which features in the Metabolomics Society pages that accompany this issue, and of course to visit their web site: http://www.meta bolomicssociety.org.

Turing my attention to the journal, we have also had another very successful year. Our impact factor rose again by $\sim 0.9$ to 4.505 . In Volume 8 issues $1-6$ we published 105 papers and a single Editorial and also produced a Special Issue entitled 'Data Analysis Methods for

R. Goodacre $(\bowtie)$

School of Chemistry and Manchester Interdisciplinary

Biocentre, University of Manchester, 131 Princess Street,

Manchester M1 7DN, UK

e-mail: Roy.Goodacre@manchester.ac.uk
Metabolomics' which contained 16 papers and an Editorial; I am very grateful to Guest Editors Johan Westerhuis and Jeroen Jansen for their very hard work and enthusiasm in putting this together-it contains some great reviews and primary papers.

Earlier in the year I was fortunate enough to attend Royce Murray's retirement party at Pittcon 2012 (11-15 March 2012 in Orlando) and chatted with Jonathan Sweedler - the new Editor of Analytical Chemistry-I wish Jonathan all the very best in his new role. I spent a few moments with Royce first of all thanking him for giving a young postdoc from Wales the opportunity to publish his first paper in Analytical Chemistry in 1994 (Goodacre et al. 1994), a monster-sized 16 page article on pyrolysis MS and neural nets. We laughed when I also told him that he sent me his editorial entitled 'Lengthening Research papers: Conciseness is Next to Godliness' (Murray 1995) when I sent my second paper in for review (Goodacre and Kell 1996). This was also too long and despite some necessary condensing still ended up at 10 pages! It was nice to finally meet Royce and I wish him a very long and happy retirement.

Since we have been publishing Metabolomics the average article length has been between 10 and 12 pages, and recently seems to be creeping upwards. I would therefore encourage all potential contributors to read Royce's editorial; even though it is 18 years old it is very forward thinking. Whilst the advent of electronic media has presented us with the opportunity to increase the amount of information we put into the public domain, it is generally accepted that although "the Devil is in the detail" in reality God is found in small places and thus shorter articles are likely to be better written, carefully constructed and hence more interesting, as well as more impactful. For Metabolomics there will be an expectation that the average 
length of a primary paper is seven printed pages, with a maximum of six Figures + Tables. So please remember this when you are constructing your next masterpiece to be sent to Metabolomics. It is expect that review articles will generally be a little longer, but these should like all communications be focussed and interesting.

For those of you tweeters (http://twitter.com/) Metabolomics has a twitter presence and regular updates on the Journal are tweeted via @metabolomics. Twitter is become a very popular place to microblog and the Metabolomics Society and the next society's meeting, hosted by Dave Watson and colleagues in Glasgow Scotland from 1-4 July 2013, have also both recently joined the Twitosphere. You can follow them for information and updates via: @MetabolomicsSoc and @Metabolomics13.
I hope that 2013 is very good to you all and that you have a successful and peaceful year.

\section{References}

Goodacre, R., \& Kell, D. B. (1996). Correction of mass spectral drift using artificial neural networks. Analytical Chemistry, 68, 271-280.

Goodacre, R., Neal, M. J., \& Kell, D. B. (1994). Rapid and quantitative analysis of the pyrolysis mass spectra of complex binary and tertiary mixtures using multivariate calibration and artificial neural networks. Analytical Chemistry, 66, 1070-1085.

Murray, R. (1995). Lengthening research papers: Conciseness is next to godliness. Analytical Chemistry, 67, 19A.

Saini, A. (2012). London's olympic drug testing lab to become national phenome center. Science, 337, 513. 